\title{
Physical and Thermodynamic Properties of Trifluoromethane
}

Y. C. HOU and J. J. MARTIN

The University of Michigan, Ann Arbor, Michigan

Trifluoromethane is commonly called fluoroform after the corresponding chlorocompound, chloroform. It is also known in the trade as Freon-23 refrigerant, and has various low-temperature applications. For the design of refrigeration units using trifluoromethane it is essential that the physical and thermodynamic properties of the compound be available over the desired ranges. The reported data on trifluoromethane are far from complete and are in some discrepancy among different investigators $(1,2)$.

The present investigation included determinations of the vapor pressure, saturated liquid density, critical constants, pressure-volume-temperature behavior, and heat capacity at zero pressure over the desirable ranges.

The sample of trifluoromethane, supplied by E. I. du Pont de Nemours and Company, was obtained from middle cuts in repeated fractionation processes and was therefore of very high purity. According to du Pont's analysis (3) the liquid phase had a moisture content of 0.0005 wt. $\%$, and the vapor of the cylinder contained 0.021 vol. \% noneondensables in liquid nitrogen.

\section{EXPERIMENTAL WORK}

\section{Vapor Pressure}

The measurements were made by a static method over the range of $254^{\circ}$ to $537^{\circ} \mathrm{R}$., which is equivalent to a pressure range of 0.25 to $690 \mathrm{lb}$./sq. in. abs. Two sets of equipment were designed for different pressure ranges. The low-pressure equipment, shown in Figure 1, was used for pressures up to $1.5 \mathrm{~atm}$. abs. and was mostly made of glass. The highpressure equipment, made of steel, as shown in Figure 2, was used for pressure determinations from $1.5 \mathrm{~atm}$. to the critical point (about $700 \mathrm{lb} . / \mathrm{sq}$. in.).

Trifluoromethane was condensed in the isoteniscope at low temperature after the system had been evacuated down to a pressure of a few microns of mercury with a combination of Hyvac and mercury diffusion pumps. Then the isoteniscope was kept at constant temperature by submerging it in a constant-temperature bath. The temperature of the bath was measured by a platinum-resistance thermometer which had been calibrated by the National Bureau of Standards. The pressure was measured when the equilibrium between the vapor and liquid trifluoromethane was reached. The low-

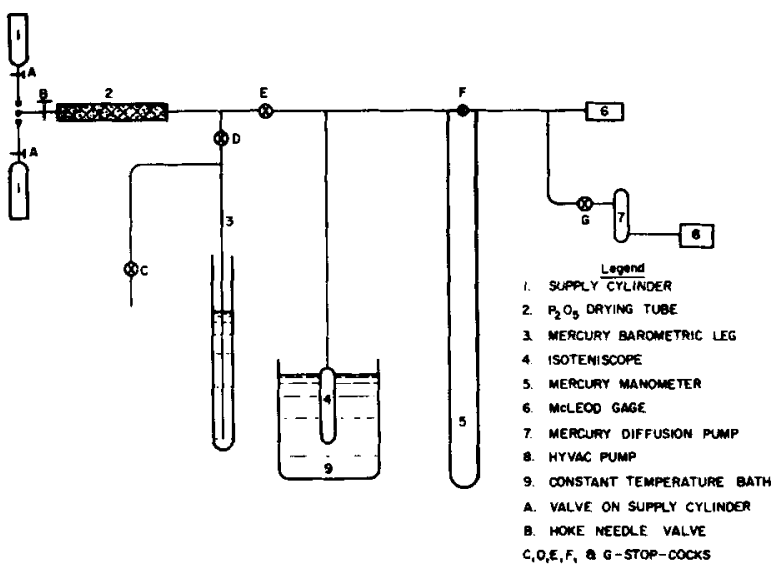

Fig. 1. Low-vapor-pressure equipment.

boiling impurities such as air were removed by letting a part of the liquid boil off. The equilibrium pressure was again measured, and the boil off and pressure measurement were repeated until a constant equilibrium pressure was obtained. This constant pressure was taken to be the vapor pressure of trifluoromethane at the temperature of the surrounding bath. The pressure in the low-pressure equipment was measured by a mercury manometer, and that in the high-pressure equipment was measured by pressure gauges. The gauges were calibrated against a Mansfield and Green dead-weight tester before and after each charge of trifluoromethane was made to the isoteniscope.

\section{Saturated Liquid Density} and Critical Temperature

The saturated liquid density of trifluoromethane was determined from $370^{\circ}$ to $538^{\circ} \mathrm{R}$. by the method described by Benning and McHarness (4). The technique employed in the measurement was to find the temperature at which the density of the saturated liquid matched that of a precalibrated density float.

The critical temperature was determined as the average temperature at which the liquid meniscus would appear and disappear; it was found to be $538.33^{\circ} \mathrm{R}$. for trifluoromethane.

\section{Pressure-Volume-Temperature Behavior}

The pressure-volume-temperature studies were carried out as a series of approximately constant density measurements. The ranges of variables were from $400^{\circ}$ to $710^{\circ} \mathrm{R}$. in temperature, 1 to $60 \mathrm{lb} . / \mathrm{cu}$. ft. in density, and 50 to 2,000 lb./sq. in. abs. pressure. The equipment is sketched in Figure 3. Trifluoromethane was charged into the steel bomb after it had been evacuated to a pressure of a few microns of mercury. The vapor in the connecting line was recovered into the recovery tube by cooling the latter with liquid nitrogen. The weight of trifluoromethane charged was calculated from the weights of the storage bulb and recovery tube before and after the charging. The whole system was kept submerged in a large constant-tempera-
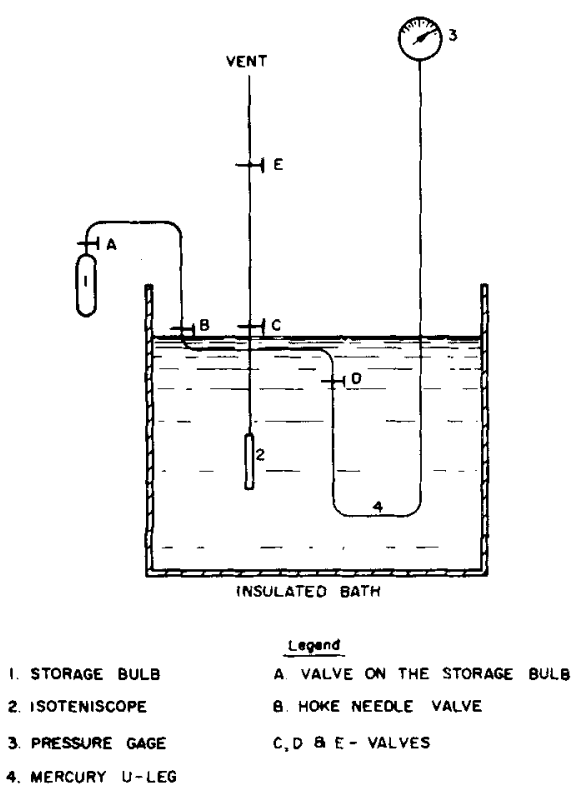

Fig. 2. High-vapor-pressure equipment. 


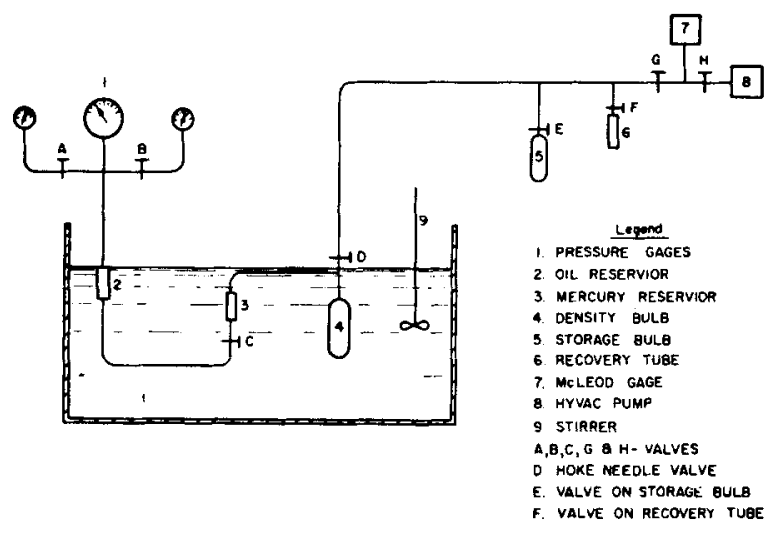

Fig. 3. Pressure-volume-temperature equipment.

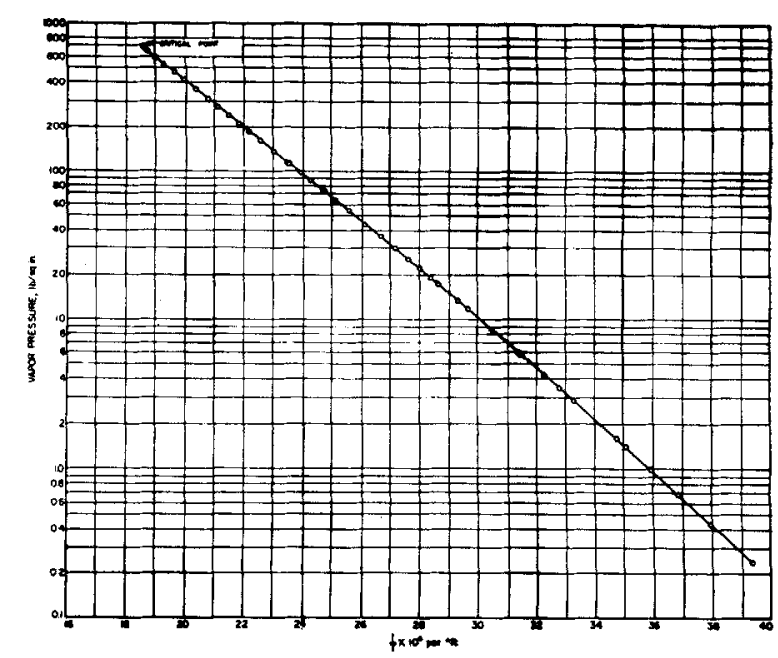

Fig. 4. Vapor-pressure data.

Tabie 2. Experimental. Saturated Liquid-Density Data

ance thermometer. A series of pressure and temperature measurements for one charging of trifluoromethane gives an approximate isometric. (If the bomb were perfectly rigid for all temperatures and pressures, a true isometric would be obtained.)

After the isometric had been completed, the trifluoromethane in the system was recovered and replaced in the storage bulb and recovery tube. From the weights of the bulb and the tube before and after the recovery the weight of trifluoromethane recovered from the system is known. The weight of trifluoromethane charged and recovered had to agree within a few hundredths of a per cent or the run was rejected because of apparent leakage. Two steel isometric bombs were used in this work. One, with a volume of about 600 cc., was used for higher density isometrics, and the other, with a volume of about 4,100 cc., was used for lower density runs when the pressure did not exceed $300 \mathrm{lb} . / \mathrm{sq}$. in. The volume of each bomb was calibrated carefully by weighing when evacuated and when filled with distilled water. Pressure gauges with suitable ranges were used for measuring all pressures. Each gauge was calibrated against the Mansfield and Green dead-weight gauge tester before and after each isometric run.

\section{RESULTS AND CORRELATIONS}

\section{Vapor Pressure}

The data are plotted as $\ln P$ vs. $1 / T$ in Figure 4 and tabulated in Table 1. The curve shows a definite $S$ shape as emphasized by Thodos (5). For this reason the simple Clausius-Clapeyron equation, the Antoine equation (6), or even the Kirchoff-Rankine-Dupré equation $(7,8)$ would not give satisfactory representations of the data, since the inflection of the curve is not predicted by these algebraic forms. It was concluded that at least one more term must be added to modify the Kirchoff-Rankine-

$\begin{array}{cc}\begin{array}{c}\text { Temperature, } \\ { }^{\circ} \mathrm{R} .\end{array} & \\ 370.79 & d_{1}, \mathrm{lb} . / \mathrm{cu} . \mathrm{ft} . \\ 454.14 & 86.587 \\ 466.70 & 73.037 \\ 480.73 & 70.317 \\ { }^{*} 498.1 & 67.195 \\ 512.77 & 62.285 \\ \mathbf{5 2 9 . 7 6} & 57.429 \\ { }^{*} 529.8 & 49.322 \\ { }^{*} 533.1 & 49.233 \\ { }^{*} 534.9 & 46.459 \\ \mathbf{5 3 6 . 6 9} & 44.172 \\ \mathbf{5 3 7 . 6 0} & 41.827 \\ & 39.763\end{array}$

* Obtained from the extrapolation of isometric curves to saturation temperatures.

Dupré equation to take care of the reversal of the curvature. The following equation:

$$
\begin{aligned}
\ln P & =757.3398770-\frac{18311.92765}{T} \\
& -144.5142304 \ln T \\
& +0.5574904317 T \\
& -4.900054254 \times 10^{-4} T^{2} \\
& +2.17247877 \times 10^{-7} T^{3}
\end{aligned}
$$

with $P$ in pounds per square inch absolute and $T$ in degrees Rankine satisfactorily represents both the data and the general characteristics of the vapor-pressure behavior over this wide range. The average deviation between the equation and the data is $0.19 \%$, and the maximum deviation is $0.58 \%$ and occurs at the lowest pressure.

\section{Saturated Liquid Density and Critical Constants}

The data on saturated liquid densities were corrected for thermal expansion of the density float. The data are presented in Table 2 and plotted in Figure 5 as 


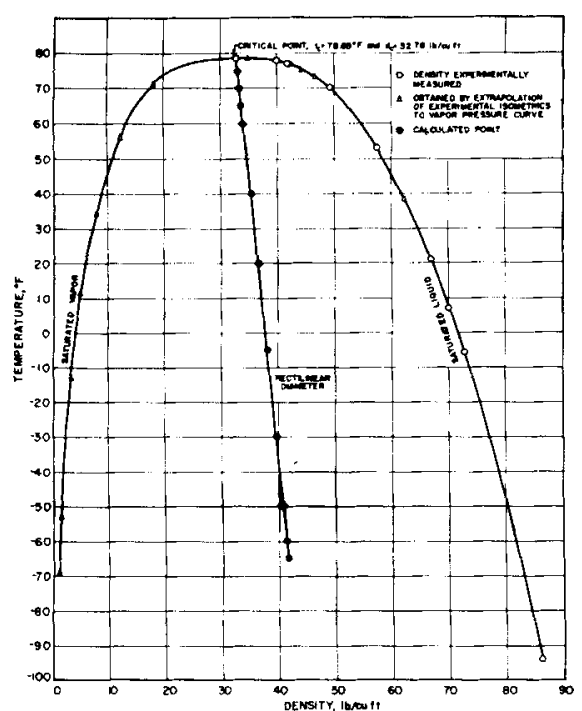

Fig. 5. Saturated liquid and vapor density plot.

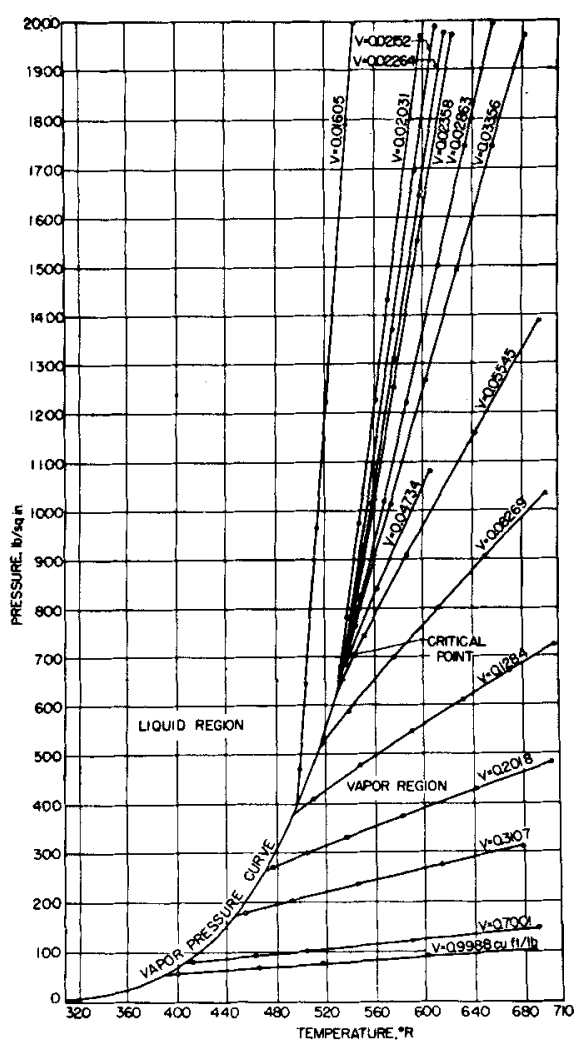

Fig. 6. Pressure-volume-temperature data for trifluoromethane.

liquid density $d_{l}$ vs. temperature $T$. Different types of equations were studied for representing the data. The possibility of equations with density expressed as functions containing only integer powers of temperature was ruled out because such forms cannot give zero slope at the critical point $\left(d T / d d_{l}=0\right)$, as do the experimental data.

A combination of the equations

$$
\frac{d_{l}+d_{v}}{2 d_{c}}=1+\frac{3}{4}\left(1-\frac{T}{T_{c}}\right)
$$

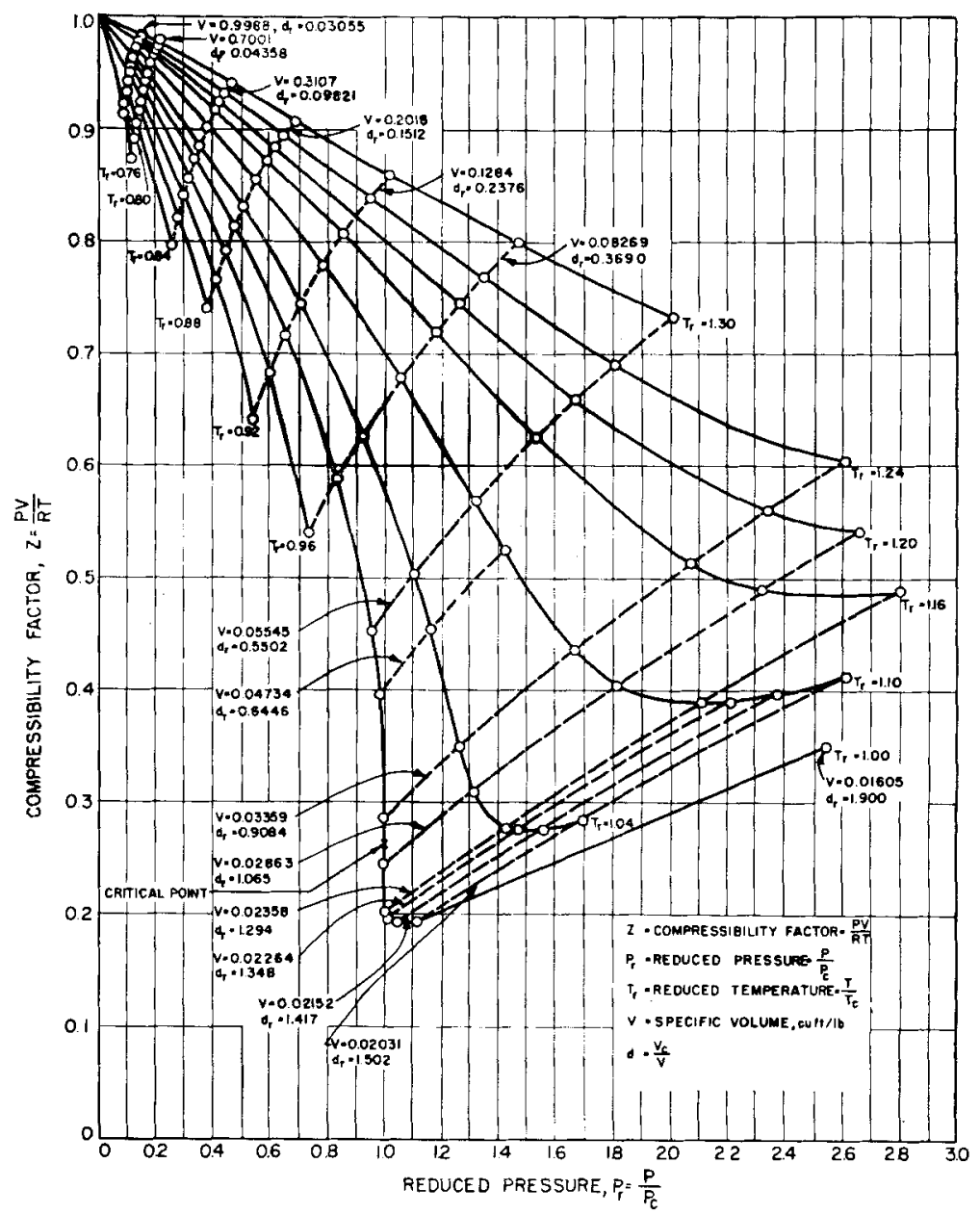

Fig. 7. Compressibility factor for trifluoromethane.

and

$$
\frac{d_{l}-d_{b}}{d_{c}}=\frac{7}{2}\left(1-\frac{T}{T_{c}}\right)^{\frac{1}{3}}
$$

given by Guggenheim ( $(9)$ yields an equation for the saturated liquid density of the form

$$
\begin{aligned}
d_{l}=d_{c}+a(1 & \left.-\frac{T}{T_{c}}\right)^{\frac{1}{3}} \\
& +b\left(1-\frac{T}{T_{c}}\right)
\end{aligned}
$$

With a parametric power of $n$ replacing $1 / 3$ in the second term, the correlation was not significantly improved. One way of generalizing Equation (4) is to consider $d_{l}$ as a function of $\left[1-\left(T / T_{c}\right)\right]^{n / 3}$,

$$
d_{l}=\phi\left(1-\frac{T}{T_{c}}\right)^{n / 3}
$$

or in a power series form,

$$
d_{l}=\sum_{n=0} a_{n}\left(1-\frac{T}{T_{c}}\right)^{n / 3}
$$

It is readily seen that $a_{0}$ must be identical with the critical density. Equation (4) may be considered as a sort of special case of Equation (6) obtained by setting all the coefficients, except $a_{0}, a_{1}$, and $a_{3}$, equal to zero. Testing the data showed that equations with $a_{0}, a_{1}, a_{3}$, and any other two $a$ 's (all the rest of the $a$ 's were put equal to zero) gave correlations with almost equally high degrees of precision. It was decided that only $a_{0}, a_{1}, a_{2}, a_{3}$, and $a_{4}$ would be used. Therefore the saturated liquid density data were finally fitted by the equation

$$
\begin{aligned}
d_{l}= & 32.7758 \\
& +63.37784\left(1-\frac{T}{T_{c}}\right)^{1 / 3} \\
& -25.30533\left(1-\frac{T}{T_{c}}\right)^{2 / 3} \\
& +144.16182\left(1-\frac{T}{T_{c}}\right) \\
& -106.13280\left(1-\frac{T}{T_{c}}\right)^{4 / 3}
\end{aligned}
$$

lb. mass $/ \mathrm{cu}$. ft.

Equation (7) represents the data with an average deviation of $0.24 \%$ and a maximum deviation of $0.67 \%$. The use of more terms after $a_{4}$ in Equation (6) may be justified for more precise work.

The critical temperature of trifluoromethane was found to be $538.33^{\circ} \mathrm{R}$. Inserting this value into the vaporpressure equation (1), one calculates the critical pressure as $701.4 \mathrm{lb}$./sq. in. abs. The critical density was determined 
Table 3. Experimental PVT Data

Volume, Temperature, Pressure, cu. ft. $/ \mathrm{lb}, \quad{ }^{\circ} \mathbf{R}$. lb./sq. in

0.9987

0.70008

400.10

466.40

517.66

602.60

687.91

412.49

463.35

504.59

590.22

691.63

0.31066

455.44

493.07

546.04

614.02

679.54

0.20158

479.89

505.55

536.95

538.33

582.52

642.47

703.64

0.12836

510.78

548.42

591.05

632.09

670.58

705.91

0.082677

519.08

539.42

576.68

613.11

650.58

700.06

0.055465

534.86

552.38

587.93

643.00

694.80

$0.047352^{*} \quad 537.68$

563.06

606.44

$0.033604 \quad 545.67$

574.22

602.73

628.97

657.22

583.05

$0.028644 \quad 545.69$

568.67

587.21

613.06

634.82

656.98

0.023589

538.33

561.00

576.86

596.89

624.23

0.022646

536.71

538.33

558.08

577.12

597.56

617.85

0.021531

536.54

538.33

559.85

575.60

593.64

610.16

0.020316

148.08

179.78

203.82

236.26

276.15

313.09

270.8

298.0

330.7

332.2

375.2

430.3

484.3

409.0

476.9

548.0

612.2

672.5

725.5

525.8

589.9

699.2

802.0

906.1

1036.5

654.3

742.7

910.0

1162.6

1392.5

684.3

834.1

1082.2

764.1

1014.7

1268.9

1496.4

1748.6

1973.1

775.0

1019.0

1224.4

1504.1

1749.9

1995.4

705.8

1024.3

1254.5

1555.7

1974.3

693.2

715.7

1014.3

1313.6

1649.1

1978.2

706.6

736.6

1097.5

1374.6

1698.1

1991.0

680.8

561.74

TABLE 3. (Continued)

$\begin{array}{ccc}\begin{array}{c}\text { Volume, } \\ \text { cu.ft./lb. }\end{array} & \begin{array}{c}\text { Temperature, } \\ { }^{\circ} \mathrm{R} .\end{array} & \begin{array}{c}\text { Pressure, } \\ \text { lb./sq. in. }\end{array} \\ & 572.13 & 1435.8 \\ 0.016045 & 598.68 & 1971.5 \\ & 500.02 & 467.8 \\ & 505.25 & 645.3 \\ & 514.58 & 965.4 \\ & 522.15 & 1226.6 \\ & 538.33 & 1793.4 \\ & 544.27 & 1997.9\end{array}$

*There was a leakage of trifluoromethane during
the run.

781.1

974.8

1229.1 from the rectilinear diagram described in the following section.

\section{Pressure-Volume-Temperature Behavior}

The data were corrected for the expansion of the density bombs, the mercury, and the oil in the whole equipment and then adjusted to true isometrics graphically with the aid of an approximate pressure-volume plot. The adjusted data were tabulated (Table 3) and then plotted as isometric curves in the pressure-temperature plane in Figure 6 and as compressibility curves in Figure 7. The isometric curves were extrapolated to intersect the vaporpressure curve on the pressure-temperature diagram. The points of intersection gave the saturation temperatures for various vapor densities. 'These saturated vapor densities together with the saturated liquid density were plotted as temperature vs. density in Figure 5. The rectilinear diameter (average of saturated liquid and vapor densities) was constructed and appeared to be straight within the precision of the data. The critical density was determined from this diagram as $32.776 \mathrm{lb} . / \mathrm{cu}$. ft., with no greater precision than $0.05 \mathrm{lb} . / \mathrm{cu}$. ft.

The adjusted PVT data were then correlated with the generalized equation of state developed by Martin and Hou (10). A slight modification was made to the orginal equation by adding one more condition to improve it in the highdensity liquid region. This was done by including a $C_{5}$ term and recognizing the fact that the isometric curve of trifluoromethane is practically straight at about twice the critical density (Figure 6). It was found for trifluoromethane that the condition of $\left(d^{2} P / d T^{2}\right)_{V}=0$ at $V=$ $V_{o} / 2.1$ gave the best representation of the data. The equation of state has the form

$$
\begin{aligned}
P & =\frac{R T}{V-b} \\
& +\frac{A_{2}+B_{2} T+C_{2} e^{-\left(k T / T_{c}\right)}}{(V-b)^{2}} \\
& +\frac{A_{3}+B_{3} T+C_{3} e^{-\left(k T / T_{c}\right)}}{(V-b)^{3}} \\
& +\frac{A_{4}}{(V-b)^{4}}
\end{aligned}
$$

Table 4. Zero Pressure Heat Capacity

Temperature,

$\begin{array}{cr}{ }^{\circ} \mathrm{R} . & C_{\boldsymbol{p}}{ }^{\circ} \\ 250 & 8.636 \\ 300 & 9.171 \\ 400 & 10.424 \\ 500 & 11.778 \\ 600 & 13.144 \\ 700 & \mathbf{1 4 . 4 4 7} \\ 800 & 15.641\end{array}$

Table 5. Comparison of Critical Constants

Critical

tempera- Critical Critical ature, Pressure, density, ${ }^{\circ} \mathrm{R}$. lb./sq. in. $\mathrm{lb}$./eu. ft.

This investigation Ruff et al. Seger

$538.33 \quad 701.42 \quad 32.78$

$\begin{array}{lll}550.8 & 691 & 32.2 \\ 518.7 & & 32.21\end{array}$

$$
+\frac{B_{5} T+C_{5} e^{-\left(k T / r_{c}\right)}}{(V-b)^{5}}
$$

Since sufficient data were taken in this investigation, the values estimated from the generalized correlations of certain parameters, $\beta, T^{\prime}$, and $m=-M P_{c} / T_{c}$, were slightly adjusted, as described in Part III of the original paper (10), to give a better representation. The final value of the constants in the equation of state are as follows:

$$
R=\text { gas law constant }
$$$$
=0.153266 \text { (lb.-forco)(cu. ft.) }
$$$$
/(\mathrm{lb} .-\mathrm{mass})\left({ }^{\circ} \mathrm{R} .\right)(\mathrm{sq} . \mathrm{in} .)
$$

$A_{2}=-5.016053028$

$B_{2}=0.00310516248$

$C_{2}=-130.8703305$

$A_{3}=0.09781899057$

$B_{3}=-0.380613864 \times 10^{-4}$

$C_{3}=3.53359637$

$A_{4}=-0.1094517281 \times 10^{-2}$

$B_{5}=1.112366387 \times 10^{-8}$

$C_{5}=-0.000182469146$

$b=0.00579112510$

These constants result from using values of the parameters as follows: $\beta=3.15$, $T^{\prime}=0.815 T_{c}, M=7.65$, and $T_{B}=$ $1,256^{\circ} \mathrm{R}$, with $P$ in pounds per square inch absolute and $V$ in cubic feet per pound mass.

The equation was developed for densities up to about 1.5 times the critical density. Up to this density the average deviation between the equation and the data is only $0.45 \%$, but right at this density the deviation is as great as $4.14 \%$.

\section{Heat Capacity at Zero Pressure}

The heat capacities of trifluoromethane at zero pressure were calculated for the 
range of $250^{\circ}$ to $800^{\circ} \mathrm{R}$. from the spectroscopic data reported in the literature. Among the various sets of assignments of fundamental vibrational frequencies $17)$, the infrared frequencies reported by Plyler and Benedict (15) with $W_{2}$ adopted. The final assignment of fundamental frequencies is as follows:

$$
\begin{aligned}
& W_{1}=3,031 \\
& W_{2}=1,137 \\
& W_{3}=700 \\
& W_{4}=W_{7}=1,372 \\
& W_{3}=W_{8}=1,152 \\
& W_{6}=W_{9}=507
\end{aligned}
$$
vibrational contribution by the use of statistical mechanics is outlined by Wenner (18). The anharmonic contribution for this compound was arbitrarily estimated to be $0.75 \%$ of the harmonic contribution at $800 \%$. and $0.3 \%$ at $250^{\circ} \mathrm{R}$. and was assumed to vary linearly with temperature in this range. The zeropressure heat capacity at any temperature is the sum of the contributions due to harmonic and anharmonic vibrations and to translation and rotation. The results of adding the various contributions were represented by the equation

$$
\begin{aligned}
& C_{p}{ }^{0}=7.327-529.47 \times 10^{-6} T \\
& +27.35341 \times 10^{-6} T^{2} \\
& -0.017189 \times 10^{-6} T^{3} \text { B.t.u. } \\
& \left.\quad \text { (lb.-mole) }{ }^{\circ} \mathrm{R} .\right)
\end{aligned}
$$

where $T$ is in ${ }^{\circ} \mathrm{R}$.

The cubic form of the equation was found desirable because the temperature range included the region where the heatcapacity curve shows a reversal of curvature. 'Table 4 gives a summary of the calculated heat capacities, which are represented by Equation (9) within a maximum deviation of $0.3 \%$. given by different investigators (11, to given by Edgell and May (17) were

The method of evaluating the harmonic

by different investigators $(1,2,19)$; however the disagreement between the earlier workers themselves is even greater. The purity of the trifluoromethane sample could be the factor that accounts for most of the discrepancies between all investigators.

The vapor pressures in the low-temperature region showed the slope of the curve of $\ln P$ vs. $1 / T$ to be numerically smaller than that given by Ruff et al. (1). As a result the normal boiling point given by Ruff et al. is $-84.4^{\circ} \mathrm{C}$. instead of $-81.8^{\circ} \mathrm{C}$. from this investigation. Seger (2) estimated the normal boiling point to be $-90^{\circ} \mathrm{C}$.

The critical constants are compared with those of the other investigators in Table 5. It is apparent that the most significant discrepancy is in the critical temperature.

The internal consistency of the PVT data taken in this investigation is shown clearly by the smoothness of the curves in Figures 6 and 7 . Unfortunately there are no published data with which to compare the PVT data taken in this work.

The statistical mechanical method of calculation of the heat capacity at zero pressure from the infrared and Raman frequencies is generally very satisfactory, if the fundamentals can be identified and the anharmonic effect is negligible. The assumptions made in this investigation on anharmonic contributions can be tested only when accurate calorimetric data are taken on the heat capacity. On the basis of other compounds it is believed that the final values of the heat capacity are probably not more than $1 / 2 \%$ in error.

The properties needed for evaluation of thermodynamic functions such as enthalpy and entropy have been determined in this investigation and represented in analytical form. The heat of vaporization can be calculated by using the Clapeyron equation with the vapor pressure and saturated liquid and vapor densities. The changes of enthalpy and entropy between any two gas states can be evaluated from the following formulas, derived for these thermodynamic properties:

$$
\begin{aligned}
& \Delta H=\int_{T_{1}}^{T_{2}} C_{V}{ }^{0} d T+\left[P V+\frac{A_{2}+\left(1+k T_{r}\right) C_{2} e^{-k T_{r}}}{V-b}\right. \\
& \left.+\frac{A_{3}+\left(1+k T_{r}\right) C_{3} e^{-k T_{r}}}{2(V-b)^{2}}+\frac{A_{4}}{3(V-b)^{3}}+\frac{\left(1+k T_{r}\right) C_{5} e^{-k T_{r}}}{4(V-b)^{4}}\right]_{V_{1}, T_{1}}^{V_{2}, T_{2}} \\
& \Delta S=\int_{T_{1}}^{T_{2}} \frac{C_{V}{ }^{0}}{T} d T+\left[R \ln (V-b)-\frac{B_{2}}{V-b}-\frac{B_{3}}{2(V-b)^{2}}\right. \\
& \left.-\frac{B_{5}}{4(V-b)^{4}}+\left\{\frac{C_{2}}{V-b}+\frac{C_{2}}{2(V-b)^{2}}+\frac{C_{5}}{4(V-b)^{4}}\right\} \frac{k}{T_{c}} e^{-k T_{r}}\right]_{V_{2}, T_{1}}^{V_{2}, T_{2}}
\end{aligned}
$$

\section{DISCUSSION}

The data obtained in this investigation do not agree too well with those reported
These equations require only the PVT relation and the heat capacity equation. With a modern automatic calculating machine a table of enthalpy and entropy values can therefore be easily evaluated from the information presented here.

\section{ACKNOWLEDGMENT}

The authors wish to express their appreciation to Donald Anthony, Ben Bray, Earl Ebach, George Gryka, Richard Reimus, and Tobey Perl for their assistance in the laboratory and in making calculations. The E. I. du Pont de Nemours and Company was very generous in supporting this study in a project sponsored at the Engineering Research Institute of the University of Michigan.

\section{NOTATION}

$\begin{array}{ll}d_{v} & \text { density of saturated } \\ & \text { vapor } \\ = & \text { critical density } \\ = & 5.475 \\ d_{c} & \\ k, B, C, a_{n}, b= & \text { empirical constants } \\ = & T / T_{c} \\ = & C_{V^{0}}+R=\text { constant- } \\ & \text { pressure heat capacity } \\ T_{r} & \text { of ideal gas } \\ C_{p}{ }^{0} & \text { constant-volume heat } \\ & \text { capacity of ideal gas }\end{array}$

\section{LITERATURE CITED}

1. Ruff, O., O. Bretschneider, W. Luchsinger, and G. Miltschitsky, Ber. deut. chem. Ges., 69, 299 (1936).

2. Seger, G., Die Chemie, 55, 58 (1942).

3. McHarness, R. C., private communication.

4. Benning, A. F., and R. C. McHarness, Ind. Eng. Chem., 32, 814 (1940).

5. Thodos, George, Ind. Eng. Chem., 42, 1514 (August, 1950).

6. Antoine, C., Compt. rend., 107, 681, $836,1143(1888)$.

7. Kirchhoff, G., Ann. Physik, 104, 612 (1858).

8. Rankine, W. J. M., Edinburgh New Phil. J., 94, 235 (1849).

9. Guggenheim, E. A., "Thermodynamics," 2 ed., Interscience Publishers, New York (1950).

10. Martin, J. J., and Y. C. Hou, A.I.Ch.E. Journal, 1, No. 2, 142 (June, 1955).

11. Glockler, G., and W. F. Edgell, $J$. Chem. Phys., 9, No. 3, 224 (March, 1941).

12. Rank, D. H., E. R. Schull, and E. L. Pace, J. Chem. Phys., 18, No. 6, 885 (June, 1950).

13. Claassen, H. H., and J. R. Nielsen, J. Opt. Soc. Amer., 43, No. 5, 352 (May, 1953).

14. Bernstein, H. J., and G. Herzberg, J. Chem. Phys., 16, No. 1, 30 (January, 1948).

15. Plyler, E. K., and W. S. Benedict, J. Research Natl. Bur. Standards, 47, No. 3, 202 (September, 1951).

16. Rix, H. D., J. Chem. Phys., 21, No. 6, 1077 (June, 1953).

17. Edgell, W. F., and C. May, J. Chem. Phys., 21, No. 10, 1901 (October, 1953).

18. Wenner, R. R., "Thermochemical Calculations," 1 ed., McGraw-Hill, New York (1941).

Manuscript received November 11, 195\%; revision received August 22, 1958: paper accepted August 25, 1958 . 